\title{
Sisters Who Make Waves and Contemporary Female Identity
}

\author{
Fangyi $\mathrm{Xu}^{1}$ \\ ${ }^{1}$ School of Journalism and Communication, Tsinghua University, Beijing, China \\ Correspondence: Weixiu Garden Building 16-308, Peking University, Haidian District, Beijing 100871, China.
}

Received: March 8, 2021

Accepted: March 29, 2021

Available online: April 13, 2021

doi:10.11114/ijsss.v9i3.5211

URL: https://doi.org/10.11114/ijsss.v9i3.5211

\begin{abstract}
The online variety show Sisters Who Make Waves has rapidly become highly popular and is one of many online shows dominated by young idols creating a group portrait of many successful sister identities. Various film and television dramas such as Nothing But Thirty and To Dear Myself have also depicted middle-aged and adult women. From the feminist perspective, mature and independent female images are a new feature of these online film and television shows. We found that women who participate in literary and creative activities are increasingly speaking in their own voices, that the sisters' independent images have important cultural symbolic significance, and that these new images form an imagined community among the audience. However, we must be vigilant about the impact of new media's commercialization on new women's images.
\end{abstract}

Keywords: subject, female image, gender identity, imagined community

On June 12, 2020, Mango TV launched a self-made team talent variety show featuring women. The show, titled Sisters Who Make Waves ${ }^{1}$, featured 30 female actors born before 1990. The show followed their training processes and depicted them as they performed and were evaluated. They were also shown behind the scenes in terms of personal growth and interpersonal relationships, presenting a group portrait of women over 30 and using the slogan, "being beautiful after 30 and allowing youth to return." The show quickly stood out in the increasingly saturated variety talent show market and set off a nationwide craze among females. Why is this variety show, which breaks traditional gender stereotypes, so popular? In this study, we analyze the show from the perspective of female subjectivity, discuss how they have become the subjects of variety shows, assess the social symbolic meaning of the sister image, and identify the potential risks of knowledge production for female images in the new media era.

\section{Females as the Subject of Creation}

In the mid-1970s, Laura Mulvey, a feminist film theorist, wrote the article "Visual Pleasure and Narrative Cinema," in which she proposed the concept of the "gaze" under the lens. She categorized the gaze into three types: that of the camera, that between characters and that of the audience. She argued that these three types of gazes are consistent with the male voyeuristic gaze of females, which mainstream movies have always treated males preferentially and that visual pleasure has always been shaped such that men are looking and women are being looked at. From this perspective, the female audience recognizes either the active masculine role or the sacrificial heroine (Mulvey, 1975). Later, her theory is criticized as patriarchal overdetermination, to which she responds that she has indeed overlooked changes in scripts and audiences (Mulvey, 1989). Modern and postmodern feminist film theories are more concerned about questions such as "Who is creating?" "For whom?" "Who is looking?" etc (Chaudhuri, 2006). SWMW provides the best case for understanding the characteristics of Chinese women's visual pleasure contemporaneously and its intrinsic mechanism. The sisters pioneered and portrayed new images of feminists subverting, flipping, or destroying the male gaze and are becoming the main force of new media as its subject.

What kind of aesthetic narrative does a variety show create? Variety reality shows create a program narrative through program planning (scripts) and actors' improvised performances. On the one hand, such a narrative structure reflects the true gender identity, perspective, and discourse of the participants; on the other hand, it is guided by the show's core value, which is based on the current society's understanding and interpretation of female consciousness. Thus, the

\footnotetext{
${ }^{1}$ For any other references to "Sisters Who Make Waves", we will use: "The Sisters" or "SWMW", and SW.
} 
public's expectations of women's problem awareness and independent female roles have established and matured, so this type of show is developed to provide a platform and imaginative space for social discussion. What kind of heroine will be created? How will the story and script form the female narrative? These are important questions in the creation of both traditional and new media. According to Jinhua Dai, "Although China and even the world's history and civilization are full of female appearances and discourses about women, their true identities and discourses have become an eternal 'absentness while present...' Females' dilemma emerges from the prisons of the language and norms, the difficulties of self-identification, and the siege and confusion of repeated mirages." (Dai, 2015) Therefore, it is a difficult political task to break through the barriers of male discourse and express female actual existence, the core of which is to break through the traditional model that "female" gains meaning only by comparison to "male", i.e., to open new female themes and narrative methods. The sisters became the protagonists in the show's creation, with their own voices dominant in the narrative perspective and content.

In terms of the production team, the variety show is run mostly by women. Wenxi Huo, the general counsel to the show's production team, is a successful woman in the performing arts, modeling, and agent circles and was herself an agent at the age of 21, which demonstrates her strong bargaining power. Her attitude is to always be in combat form; she claims that, for her, work makes her happy and contented. She has won the "2014 Hard-work Award" from the Weibo Awards Ceremony; the 2015 "Women's Media Award" co-sponsored by the UN Women and the Netease Woman Channel; and the best variety show producer award, "2017 iQIYI Scream Night." Among these, the "Women's Media Award," which was initiated in 2010 by the UN Women and the Netease Woman Channel, is a major award themed at gender equality in China. In 2015, Wenxi Huo received the award and attended the awards ceremony, at which she told reporters, "In recent times, you will notice that female status is improving. Many large organizations and companies, which were previously headed by men, are now headed by women. Approximately 10 years ago, for example, many people sent me their photos and addressed me as 'Uncle Wenxi Huo,' mistaking me for a man. But recently, there have been many successful women, regardless of the industry. I really hope to be the best in the industry I am in and to be accountable for myself and my boss as well." (Huo, 2015) The new media's visual sense has changed the image of successful people, who were formerly envisioned as uncles, while giving women their true identity and status. Wenxi Huo has become a role model for countless women who want a career in show business. Hua Du, another producer, is also riding the developmental tide of China's Internet entertainment industry, becoming one of its leaders. In June 2009, Hua Du founded Yuehua Entertainment, which, in ten years, she grew into a well-known entertainment company. On March 7, 2019, on the "Her World • Her Strength" China Women's Leadership Forum cosponsored by Zhaopin and the UN Women, Hua Du noted that, in the current entertainment industry, the proportion of women is particularly high and that they assume essentially all roles, including agent, promoter, planner, and business manager, with a very high work intensity (Anonymous, 2019).

Whether it is the actors participating in the show or the personnel working behind the scenes, the main players are mostly women playing multiple roles - i.e., wife, mother, and team leader - but they continue to stride forward. Perhaps it is their personal experience that enables them to see the efforts and contributions of women in the entertainment industry and the fact that these women are omitted from the market, unrelenting, and still outstanding after entering middle age. Regardless of the original intention of $S W M W$, the end product portrays the vitality of independent and hardworking women in the entertainment industry. These women project images of themselves as having independent personalities with a strong sense of self-confidence, an exploratory spirit, and a teamwork mentality. This portrayal represents an important cultural creation, in which, as female creators, these women can instinctively realize the mentality of women both as mothers and as those who desire to be independent. Designing the contest system, determining which questions to ask, making editing decisions, etc., are nuanced creative processes that reflect the production team's understanding of the relationship between women and gender. These types of creative subjects are destined to make The Sisters a work dominated by a female discourse system.

From the perspective of gender comparison, the fact that the sisters appear as middle-aged women in a variety show and assume a dominant role there shows that they are finally being seen. Male entertainers in the Chinese film and television entertainment market are always represented, at any age, whether it be as adolescents, the middle aged or the elderly. They have an appropriate position in the film and television narrative, with recognizable social roles and values. At different ages, male actors have rich character images. Young actors have youthful roles. Adult to middle-aged actors play the roles of teachers, doctors, entrepreneurs, etc. in films with various themes such as spy, crime, public security, military, family ethics, romance films, etc. Finally, elderly actors play roles corresponding to their experience and authority spanning a variety of subject types. In contrast, the space for female roles is much narrower. Except for youthful themes, women after adulthood exist almost exclusively in two categories - i.e., family ethics and rural themes - and have very limited space in dramas with professional and war themes. Therefore, when middle-aged female 
actors have the right to discourse, their discursive power will overflow, and the energy that is denied them by film and television is then expanded when they participate in variety and reality shows. In reality shows, participants plan a narrative according to their own characteristics, allowing them to show their character designs, images, personalities, interpersonal relationships, etc., and ultimately their values. Due to the "realistic" characteristics of reality shows, a large number of female viewers can quickly subscribe to them, engaging in online dissemination and public discussion. From the artists to the practitioners, from the viewers to the Internet users, women have an abundance of power denied to them in other spheres, which may have contributed to the popularity of reality shows such as $S W$, and the audience activity they generate. Then, what makes the show resonate with the audience?

\section{The Community of Female Gender Identity and Imagination}

The charm of 30 sisters, each with a unique personality and achievement, has earned it high television ratings, owing to the vital link between the sisters and their audience. $S W M W$, has a critically acclaimed rule: the production team recruits 500 all-female reviewers from the audience onsite. This rule allows the female audience to be foregrounded, thus eliminating the male gaze from the show's structure. The male gaze refers to the viewing by straight men, in which women are positioned as objects of men's desire: females are sexualized, objectified, and watched. Having women review women demonstrates that females are more appreciative of femininity charm, are more understanding of women, and are more willing to help themselves. The sisters are not restrained from speaking their minds or from being daring in their style. They have significant experiences and are recognized, debated about, or criticized by the audience as real people. The audience is eager to see diversity flourishing and to find themselves in the sisters. The sincere interaction between the reality show and the audience as one another's subjects has established an imagined community in gender identity terms. As a community, they do not know each other, but their sincerity and empathy cause the viewers to greatly identify with the sisters with respect to their independence, their courage in taking responsibility, their positive attitude towards life, and the new female image they project that shoulders the loads of both work and life. In this way, the sisters and their audience realize psychological empathy, mutual understanding, and mutual support. The sincere interaction between the reality show and the audience has caused female audiences to be more empathetic to the female images portrayed in the show while rethinking their own female identity. Furthermore, based on the platform, they engage in online discussions more extensively to disseminate new ideas and consciousness about women.

Gender identity is closely related to the socialization process of an individual's growth. People acquire perceptions and norms about social roles, gender interaction rules, and women's values when they interact with families, schools, and peer groups, according to which they implement their gender roles. In the Internet era, various media have become important for shaping, learning, and expressing people's gender values. As modern culture has been promoted globally, a new generation of females has become independent, capable, and active individuals. However, the traditional gender concept still lingers in society, while the mainstream masculine culture does not accept the rise of this new generation of women. The resulting cultural tension is responded to unambiguously in The Sisters in the form of new media. Traditional women who are dependent on men for a living or who are treated as delicate vases have already become a figment of traditional men's imagination, while modern, independent, and self-pleasing female images are accepted and loved by the audience. The rich images of sisters who are sincere, versatile, hardworking, beautiful, and diligent allow the audience to see that sisters as subjects are colorful and independent selves, although some of them may be scheming or aloof and thus lacking in etiquette or overconfident. They have broken traditional gender stereotypes by flexibly using verbal and body language, so females inhabit the stage as individuals. The gender identity achieved by the new female image is mainly characterized by an independent personality.

First of all, the new female image has broken the patriarchal cultural requirement that only marriage makes women perfect. In the traditional gender role relationship, the evaluation of a woman is often based on who her husband is, and girls who do not fancy marriage are often regarded as leftovers by society while divorced women are assumed to live an unhappy life. However, the sisters are proving to society that, as independent people, they are good enough and do not need their husbands to present themselves. They can still experience improved lives and find love after leaving a patriarchal husband. Therefore, the value as independent individuals is highlighted. Sha Jin, a show participant, maintains that "we are not commodities that are leftover but individuals with self-consciousness. The so-called concept of leftover women is nothing but the dross of the patriarchal society forcing women into marriage." (KY, 2019) Clearly, in the transition from tradition to modernity, those who are eager to break the tradition have their own dilemmas, and the uncompromising attitude also requires mutual support from peers and the participation of men in the fight for gender equality. $S W M W$ also has various male viewers. For example, Xiaoming Huang, a witness group member, is a man. The ideological impact brought by the show is also significant for traditional males. 
Secondly, the new female image has defined a positive style of feminine beauty, especially the beauty of the independent female personality. According to life cycle theory, each age and stage of an individual from birth to death exhibits a different life path. Regardless of gender, an individual generally experiences diverse life events, such as birth, schooling, employment, marriage, childbirth, divorce or widowhood, children's growth and marriage, retirement, and, at every turning point, an individual must resolve crises, assume new social roles and face life's tests. Each life stage offers a unique life experience and shows the beauty of human nature. Men and women carry different gender-related divisions of labor at different life cycle stages. Under the traditional male gaze, feminine beauty is often portrayed through the image of flower and jade, referring to the beauty of young girls, while middle-aged and married or old women are perceived as withered flowers or dying willow trees, destined to withdraw from the shining stage. Women present their independent roles in the gender-interactive relationship that resonates with the audience. Liti Zhong, aged 50 , is the still-active mother of three daughters, of which the eldest is 22 years old. Ning Jing, who has a 22-year-old son, still shows her independent characteristics as well as her feminine ones. Women's beauty is no longer monopolized by young girls. Moreover, the hallmark of mature womanhood lies in their ability to support their partners, their life experiences, and the rich and layered beauty they have from the inside out.

Thirdly, The Sisters shows the front- and backstage of women's lives and thus their work and lives. According to the theory of symbolic interactions, people's lives are divided into a front- and a backstage as if they were played out in front of an audience. People show beauty to others or even pretend to be beautiful in the foreground, while, in the background, they are their real selves, showing the unsatisfactory sides of jealousy, pride, or frustration. The process of daily training the camera lens onto the sisters shows their difficulties, allowing the audience to understand the intrinsic connection between hard work and reward. The new media showcases the sisters' lives in all their aspects, so the audience knows that life is not simply the superficial lure but the diligence and sweat that occur in backstage. Having seen the hard training and vigorous assessment of the sisters without their auras, the audience can reflect on middle-aged anxiety in society, an anxiety with which female, and even male, audiences can resonate.

Funally, The Sisters has broken traditional gender stereotypes. Jinhua Dai once pointed out that Chinese culture has historically used two female images to represent women's destiny. Females always face two images or dilemmas: Hua Mulan and Qin Xianglian. Hua Mulan is a feminine make-up technique used in public spaces, by which women must pretend to be men to gain social status. Qin Xianglian refers to an old tradition of women in the private sphere, in which they can gain social recognition only by abiding by the rules, behaving themselves, and waiting their turn (Dai, 2007). Nengjing Yi, aged 52, can still conquer the audience through sensual dance; the 50-year-old Liti Zhong appears as a mermaid; the 38-year-old Qian Wan learns to play guitar and sing; and the 37-year-old Xin Wu learns to dance; the 33-year-old Yuqi Zhang strives for the C-list. They are no longer portraying either the image of the traditional weak woman Qin Xianglian or that of the Hua Mulan, resembling a man. They do not exist, but have natural expressions of "I think" and "I am the way I am," thus depicting complete individuals with emotions and feelings.

In short, The Sisters expresses and caters to the aesthetic needs of modern women's personality independence and bestows mature, personality-independent, and hardworking women an important social value. Relying on the existence of the new female imagined community, the new feminist media is quietly, consciously or unconsciously, narrating the new women's beauty. From the perspective of cultural symbolism, the phrase "making waves" is fitting in that it implies that, in their growth process, females must ride the tide by breaking the waves, becoming themselves and being extremely powerful, which takes great bravery. Nevertheless, the commercialization of programs still needs reflection.

\section{Reflections on Commercialized Society Integrated with Media}

In a commercialized society, the success of $S W M W$ is manifested in market performance. Mango SuperMedia, the main producer of $S W$, has earned approximately 500 million yuan in sponsored advertising revenue from the show, which has spurred the growth of company membership and advertising revenue. According to QuestMobile data, Mango TV users' usage time increased by $40.2 \%$, and the daily and monthly activities increased by $45.2 \%$ and $49.1 \%$, respectively, making it China's fastest growing video platform. Within the first week of the show's broadcast, the company's stock price rose nearly $30 \%$, and its market value increased by more than 20 billion yuan, causing it to reach the 100 billion market value mark and making it the cultural media company with the highest value in the A stock market. Now, its market value is approximately equal to four times that of Wanda Film, three times that of Enlight Media, nine times that of Huace Film \& TV, and 11 times that of Huayi Brothers Media (Kang, 2020). These numbers show that The Sisters is being promoted as a commodity, and the consumers' traditional role, i.e., as the audience, in terms of the click-through rate of the new media has caused the show to become such. Formerly traditional consumers have become "productive consumers," who disseminate the information resources they own and who produce information through a shared platform for more people to consume. The success of the sisters also indicates that women are entering the business 
world with a vision of consumptive power, and their social and mental needs will lead to the creating and shaping of a set of new female images. How can we make the new media a voice for citizens? How can we ensure it includes more women's voices? How can we bestow critical thinking and introspective ability on the producers, performers, and audiences of cultural goods? These are questions that need to be pondered and answered.

In 1985, in Amusing Ourselves to Death, Neil Postman, an American media culture scholar, revealed the historical process by which television, audio, and video have gradually replaced written language and how audiovisual art has led to a phenomenon in which social public discourse appears in the form of entertainment. The phrase "the medium is the metaphor" indicates that people use media to define their own society and lives and to form the way they understand the world (Postman, 2004). SWMW portrays a new image of women, which actively promotes a new perception of females. However, this analysis demonstrates that these sisters still fail to eliminate the modern competitive consciousness that admires winners. They cannot eliminate the symbols of reputation, qualifications, celebrity status, and wealth. Shengyi Huang and Liti Zhong have repeatedly stated that, although they are older, they will always be like 18-year-olds, showing that the sisters deliberately pursue the aesthetic standards of perpetual youth. These features of the show clearly reveal the social inequality intertwined with gender, class, and age differentiation that are societally present.

If the sisters create more audiovisual enjoyment and psychological empathy for female audiences, then, for male audiences, the show remains rooted in the traditional male gaze, in which the internalized male-centered aesthetic does not change in the presence of the feminist female image. The new gender cooperation style that challenges the male gaze or that leads men to understand gender equality cannot be achieved by shows dominated by only one gender. Therefore, we expect the audiovisual projects of the gender partnership model to have purposeful, real, and specific interactive relationships.

The sisters provide us with a model to understand the production and dissemination process of media convergence. Reality shows have caused time barriers to disappear while smart phone applications have eliminated space barriers. Applications of new communication technology have permitted viewers outside of the incident to participate, so entertainment products are becoming increasingly involved in people's lives, enabling watching and participating to become a common lifestyle. Reality shows provide a legitimate channel through which the public can peek into others' lives, while click-through rates and traffic can help the shows' creators instantly understand the audience's preferences and needs. The media convergence occurs when it takes user data as the core, diversified products as the foundation, and multiple terminals as the platform. Has this media era, which emphasizes sharing and intelligence, resulted in new ways to empower human beings, or has it more profoundly alienated the public's life? As consumers enjoy entertainment products, they believe they have acquired greater autonomy and are extremely happy because they think they have found their inner self. Furthermore, they may have collectively and unconsciously fallen into others' lives and worlds and are living their lives. This question has no answer. From a positive perspective, as the current media convergence has enabled women to become producers, performers, and the subject of viewing, the independent female images entering public life may also enable more women to establish the belief and courage to live independently, so difficulties are no longer perceived as fearful, as reflected in Li Bai's verses: "Someday, with my sail piercing the clouds/ I will mount the wind, break the waves, and traverse the vast, rolling sea."

\section{References}

Chaudhuri, S. (2006). Feminist Film Theorists: Laura Mulvey, Kaja Silverman, Teresa de Lauretis, Barbara Creed. London: Routledge. https://doi.org/10.4324/9780203357026

Dai, J. (2007). Boat of Crossing: Chinese Female Writing and Female Culture in the New Era. Peking University Press.

Dai, J. (2015). Film Criticism (2nd Edition). Beijing: Peking University Press.

Huo, W. (2015). Wenxi Huo: Women Leaders are Positive Energy for Women's Progress. Retrieved September 23, 2020, from https://lady.163.com/15/0112/21/AFPRC56G002626I3.html

Kang, M. (2020). The Stock Value of Mango SuperMedia Surpasses 100 billion yuan, and Let Us See How Mango TV Mounts on the Wind and Breaks the Waves." Huasheng News. Retrieved September 23, 2020, from http://travel.voc.com.cn/article/202007/202007101453295465.html

KY. (2019). Sha Jin, Mounting on the Wind and Breaking the Waves, Being Unmarried at the Age of 37, Just Wants To Do This. Retrieved September 23, 2020, from WeChat Public Account "KnowYourself."

Mulvey, L. (1975). Visual Pleasure and Narrative Cinema. Screen, 16(3), 6-18. https://doi.org/10.1093/screen/16.3.6

Mulvey, L. (1989). Afterthoughts on 'Visual Pleasure and Narrative Cinema'. In Laura Mulvey (Ed.), Visual and Other Pleasures. Bloomington, IN: Indiana University Press. https://doi.org/10.1007/978-1-349-19798-9 
Netease. (2019). Hua Du of the Yuehua Entertainment: Women Must Stick More to their Dreams. Retrieved September 23, 2020, from https://money.163.com/19/0307/18/E9ME26LS00258104.html

Postman, N. (2004). Amusing Ourselves to Death. Translated by Zhang, Y., Guilin: Guangxi Normal University Press.

\section{Copyrights}

Copyright for this article is retained by the author(s), with first publication rights granted to the journal.

This is an open-access article distributed under the terms and conditions of the Creative Commons Attribution license which permits unrestricted use, distribution, and reproduction in any medium, provided the original work is properly cited. 